\title{
Extraction and determination of total polyphenols and antioxidant capacity of red coffee (Coffea arabica L.) pulp of wet processing plants
}

\author{
Melkayo Geremu', Yetenayet Bekele Tola ${ }^{1 *}$ and Abrar Sualeh ${ }^{2}$
}

\begin{abstract}
Background: Coffee waste disposal from wet processing units is increasing with an increase in coffee consumption throughout the world. This not only has a limitation in terms of environmental pollution, but also high waste volume is an opportunity to extract essential bioactive compounds and antioxidants for food and pharmaceutical industries. The aim of this paper was to investigate the effects of extraction solvents and coffee cherry pulps of different varieties in terms of their yield potential for total polyphenols and antioxidant capacity.

Results: Results show that coffee cherry pulps from different varieties extracted by different solvents showed significant effects. Among the studied varieties, coffee cherry pulp from Ababuna variety was found to be superior in total polyphenols (1809.9 mgGAE/gm) content and antioxidant capacity (70 \% inhibition). This value was followed by pulp from the Dessu variety. But the pulp from variety 741 , extracted using aqueous ethanol solvent, showed inferior results for both total polyphenol content and antioxidant capacity. Among the solvents studied in this work, aqueous methanol responded better for pulps of all varieties except Dessu which responded better for aqueous acetone solvent.

Conclusions: Red coffee cherry pulp discarded as a waste from wet coffee-processing plants can be used as a raw material to extract important value-added products like polyphenols and other antioxidants. These compounds can be used as biological additives in food and pharmaceutical industries to fight chronic diseases and aging. Furthermore, the study shows the possibility of extracting value-added bioactive compounds from biological wastes.
\end{abstract}

\section{Background}

Bioactive compounds are value-added products, justifying their isolation from industrial wastes [1]. These residues, in fact, could be an alternative source for obtaining natural antioxidants, which are considered completely safe in comparison with synthetic antioxidants $[2,3]$. Coffee is one of the copious beverages, and the worldwide production is over 105 million tons annually [4]. Industrial processing of coffee cherry is done to isolate coffee beans by removing pulp and mucilaginous parts from

\footnotetext{
*Correspondence: yetenayet@gmail.com; yetenayet.bekele@ju.edu.et 1 Jimma University College of Agriculture and Veterinary Medicine, PO. BOX 307, Jimma, Ethiopia

Full list of author information is available at the end of the article
}

cherries. To get beans for roasting, coffee is subjected to wet (washed) and dry (unwashed) processing. In the former case, red coffee cherry pulp is removed mechanically within a short period of harvesting time to produce better quality coffee beans. For every 2 tons of coffee cherries processed, nearly 1 ton pulp is generated [5]. Most of the coffee pulp generated during wet processing goes without any treatment directly to huge waste disposal sites or river streams. Toxic compounds from disposed fermenting cherries leach to the environment and pollute sources of water in the coffee-producing regions. Such ways of waste disposal have been the major environmental health challenges in coffee-growing and -processing 
areas. Moreover, such unsafe ways of waste disposal have greatly affected the terrestrial and aquatic biota [6].

So far, different attempts have been made to use the pulp from wet processing plants. However, a study showed that coffee pulp cannot be used as an animal feed, mainly due to its toxic components such as caffeine, mineral salts, amino acids, tannins, phenols and other polyphenols [7]. On the contrary, it is used to make compost to enrich soil fertility or as a mulch material to prevent evaporation of moisture and to control weed growth. New aspects concerning the use of this waste as a raw material to extract important bioactive components is the other aspect to minimize environmental pollution through the value addition process. Because of their high value nature and less cost of extraction methods, extraction and use of bioactive compounds from waste pulp as a food additive are gaining interest $[8,9]$. Coffee pulp as a by-product contains associated bioactive compounds like polyphenols with good antioxidant properties, which endow additional health benefits. Studies $[10,11]$ also indicated the possibility of extraction of total polyphenol compounds and antioxidants from coffee pulp to manage coffee waste. However, the effect of varieties and extraction solvents on the total polyphenols and antioxidant capacity has not yet been studied. Therefore, the study aimed to investigate the effect of variety and extraction solvents on total polyphenols and antioxidants capacity of coffee cherry pulp of wet processing stations.

\section{Methods}

\section{Experimental materials and sample preparation}

Coffee pulp samples from Ababuna (hybrid of $741 \times$ Dessu), pure line varieties of 741, Dessu and 74110 were obtained at full maturity and ripening stages from Jimma Agricultural Research Center, Ethiopia. Ababuna was included purposefully for two reasons. First, due to its high yielding capacity, coffee cherry pulp from this variety will be high in the future during massive production. The second reason was to investigate the combined effect of the two lines on the total polyphenol and antioxidant capacity of cherry pulp from the hybrid. Before the pulping process, coffee cherries were sorted to remove over-ripe, deteriorated and bruised ones. Pulping was done on the same date of harvesting using a manually operated coffee pulper. The pulp was drained of excess water, blotted on tissue paper and stored at $-18{ }^{\circ} \mathrm{C}$ for further investigation.

\section{Extraction of the sample}

The coffee cherry pulp sample was extracted according to Saewan et al. [12] and Jagtap and Bapat, [13]. For extraction purpose, three solvents (aqueous $80 \%$ methanol, $80 \%$ acetone and $80 \%$ ethanol) were used. Ten g coffee pulp was mixed with $100 \mathrm{ml}$ of the respective solvent and ground for $3 \mathrm{~min}$ in a homogenizer and transferred to conical flask. The ground samples were extracted using the maceration technique by soaking the samples in the solvents for $24 \mathrm{~h}$ at room temperature, followed by filtration using Whatman No. 1 filter paper. The filtered extract was used to determine the total polyphenol content and antioxidant capacity.

\section{Determination of total polyphenol content}

Total polyphenol content (TPC) of coffee pulp extract was determined using the Folin-Ciocalteu method [14]. Folin-Ciocalteu reagent, a mixture of phosphotungstic $\left(\mathrm{H}_{3} \mathrm{PW}_{12} \mathrm{O}_{40}\right)$ and phosphomolybdic $\left(\mathrm{H}_{3} \mathrm{PMo}_{12} \mathrm{O}_{40}\right)$ acids, is reduced to blue oxides of tungsten $\left(\mathrm{W}_{8} \mathrm{O}_{23}\right)$ and molybdenum $\left(\mathrm{Mo}_{8} \mathrm{O}_{23}\right)$ during phenol oxidation. This reaction occurs under alkaline condition provided by sodium carbonate. The intensity of blue color reflects the quantity of polyphenol compounds, which can be measured using a spectrophotometer [15]. Gallic acid was used as a standard and the total polyphenols were expressed as $\mathrm{mg} / \mathrm{g}$ gallic acid equivalents (GAE) from the calibration curve $\left(R^{2}=0.996\right)$ using gallic acid. Gallic acid $(0.5 \mathrm{~g})$ was accurately weighed into a $10 \mathrm{ml}$ volumetric flask, dissolved in $10 \mathrm{ml}$ absolute methanol and the solution was made up to $100 \mathrm{ml}$ with $80 \%$ of the same solvent. For standard curve $0,1,2,3,4$ and $5 \mathrm{ml}$ of standard solutions were added into a $100 \mathrm{ml}$ flask and diluted to give 0 , 50, 100, 150, 400 and $500 \mathrm{mg} / \mathrm{l}$ of gallic acid. Then, $0.5 \mathrm{ml}$ of each sample was introduced into test tubes and mixed with $2.5 \mathrm{ml}$ of a tenfold dilute Folin-Ciocalteu reagent and $2 \mathrm{ml}$ of $7.5 \%$ sodium carbonate. The tubes were covered with aluminum foil and allowed to stand for $30 \mathrm{~min}$ at room temperature before the absorbance was read at $765 \mathrm{~nm}$ using UV/Vis spectrophotometer (T80, China). The samples were prepared in triplicate for each analysis and the mean value of absorbance was obtained.

\section{Determination of total antioxidant capacity}

Free radical scavenging assay or DPPH (2,2-diphenyl1-picrylhydrazyl) assay was done as per the method of Hemalatha et al. [16] with minor modification. One $\mathrm{ml}$ solvent extract of the samples was taken in a test tube and $2 \mathrm{ml}$ of $0.1 \mathrm{mM}$ DPPH was added. The mixture was shaken well and incubated at room temperature in the dark for $30 \mathrm{~min}$. The decrease in absorbance of the resulting solution was then measured spectrophotometrically at $517 \mathrm{~nm}$ (UV-Vis spectrophotometer, T80, China). All the experiments were performed in triplicate and the mean $\pm \mathrm{SE}$ values were reported. The scavenging activity was calculated from the control sample using the following equation:

Radical scavenging activity $(\%)=\left(\frac{A_{\mathrm{c}}-A_{\mathrm{t}} / A_{\mathrm{s}}}{A_{c}}\right) \times 100$, 
where $A_{\mathrm{c}}=$ the absorbance of the control, $A_{\mathrm{t}}=$ the absorbance of the test solution, $A_{\mathrm{s}}=$ the absorbance of the standard solution, and the $\mathrm{IC}_{50}$ value was also calculated from the graph of the percentage DPPH free radical scavenging activity versus concentrations of the samples.

\section{Experimental design and data analysis}

The experiment was laid out in two-factors factorial arrangement in complete randomized design in triplicate. Factors were coffee cherry pulp of four varieties and three types of extraction solvents as indicated above. ANOVA of the collected data were analyzed using Minitab computer software program (Version 16.0, Inc. Pennsylvania, USA). Means separation was carried out using Tukey's test for means showing significant difference at $p<0.05$.

\section{Results and discussion}

\section{Total polyphenol content of coffee cherry pulp}

Polyphenols are secondary metabolites that are produced by plants to protect themselves against plant diseases and insects, but they play important roles in human health in protecting against a number of diseases related to oxidative stress and free radical-induced damage [17]. In this study, considerable variation $(p \leq 0.001)$ was observed among the type of solvents used and pulps tested. The amount of total polyphenols recovered from different coffee pulp extracts varied from 1809.9 to $489.5 \mathrm{mg}$ GAE/g. Coffee pulp from Ababuna exhibited the highest polyphenol (1809.9 GAE/g) content when its cherry pulp was extracted with $80 \%$ methanol. However, the lowest ( $489.5 \mathrm{mg} \mathrm{GAE} / \mathrm{g}$ ) value was obtained from a cherry pulp of 741 extracted with $80 \%$ ethanol. When pulp sources were compared, Ababuna responded better to all solvent types as compared to other varieties except for the considerable effect of acetone on Dessu (Table 1). Since Ababuna is a hybrid of 741 and Dessu, the heterosis effect resulted in creating not only high-yielding hybrid vigor variety, but also superior variety in terms of total polyphenol content. However, the two pure parent lines as well as genotype 74110 and 741 exhibited lower polyphenol values, except Dessu (Table 1). This result is also in agreement with Gorinstein et al. [18] who reported that the total phenol content and antioxidant potential were significantly higher in grapefruit's hybrid than parent lines. As it is known in plant pathology, plants mainly produce phenolic compounds as a means to defend themselves against diseases and insect pests [19]. Therefore, disease or stress resistance of the hybrid may be associated with such type of metabolic boost which has a great significance in improving the bioactive content of plants for the benefit of human health.

When extraction solvents are considered, they show a significant effect on the yield of total polyphenols extracted. Methanol in all cases except acetone for Dessu showed a significant effect in extracting better total polyphenol yield. The total polyphenol content of the methanol extracts varied from $900.6 \mathrm{mg}$ GAE/g (741) (wb) to $1809.9 \mathrm{mg}$ GAE/g (Ababuna) (Table 1). This is in agreement with Siddiq et al. [20]; they reported that $80 \%$ methanol is known to be an efficient and widely used solvent system to extract natural antioxidative components, especially phenolics, from plant materials. This might be because the methanolwater mixture has high polarity and thus has greater efficacy toward extraction of polar phytochemicals such as phenolics and flavonoids. Furthermore, methanol is the most suitable solvent in the extraction of polyphenol compounds due to its ability to inhibit the reaction of polyphenol oxidase that causes the oxidation of phenolics and its ease of evaporation compared to water [21]. Turkmen et al. [22] also reported that solvents with different polarity had significant effect on polyphenol content and antioxidant activity. Similar to Ababuna, 74110 and 741 showed better extraction of total polyphenols when treated with the same solvent. However, Dessu responded better when it was treated with $80 \%$ acetone. This shows that methanol might not serve as a good extraction solvent for all varieties, and hence varietal preference for suitable type of solvent should be checked for better extraction efficiency. But from the current study, considering the concentration of total polyphenols extracted, the extraction efficiency of methanol $>$ acetone $>$ ethanol.

For the purpose of this study, polyphenol yield potential (in percent) of pulps and extraction potential of solvents were compared after taking Ababuna and methanol as a standard pulp variety and solvent type, respectively. As indicated in Table 1 (column 3), 741 showed the lowest polyphenol yield potential, even though it has a significant boosting effect when combined with Dessu. Variety 74110 exhibited almost the same result with 741, but Dessu performed better than these two varieties. Therefore, a hybridization program of coffee not only resulted in better hybrid vigor varieties for quantitative traits like yield, but also offers an opportunity to extract bioactive components from wastes to use in the food and pharmaceutical industries.

\section{Antioxidant activity of coffee cherry pulp}

An antioxidant is a molecule stable enough to donate an electron to a rampaging free radical and neutralize it, thus reducing its capacity for cell damage. These antioxidants delay or inhibit cellular damage mainly through their free radical scavenging property [23]. The DPPH scavenging assay was done for all four coffee cherry pulps and three solvent extracts, taking ascorbic acid as 
Table 1 Interaction effect of variety and solvents on polyphenol contents of coffee cherry pulp and percent yield

\begin{tabular}{llll}
\hline $\begin{array}{l}\text { Types of variety as } \\
\text { source of pulp }\end{array}$ & $\begin{array}{l}\text { Types of extraction } \\
\text { solvent }\end{array}$ & $\begin{array}{l}\text { Total polyphenol content } \\
\text { (mg GAE/g) }\end{array}$ & $\begin{array}{c}\text { Total polyphenols (\%) of varieties } \\
\text { as compared to Ababuna taking } \\
\text { methanol as a standard solvent }\end{array}$ \\
\hline Ababuna & Acetone & $1434.3 \pm 3.49^{\mathrm{d}}$ & $79.2^{* *}$ \\
& Ethanol & $1603.8 \pm 3.04^{\mathrm{c}}$ & 88.6 \\
& Methanol & $1809.9 \pm 1.33^{\mathrm{a}}$ & 100.0 \\
Average & Acetone & 1616 & 89.3 \\
Dessu & Ethanol & $1709.0 \pm 1.02^{\mathrm{b}}$ & 94.4 \\
& Methanol & $1448.4 \pm 1.01^{\mathrm{d}}$ & 80.0 \\
Average & & $929.1 \pm 2.64^{\mathrm{f}}$ & 51.3 \\
74110 & Acetone & 1362.2 & 75.3 \\
& Ethanol & $662.1 \pm 0.65^{\mathrm{i}}$ & 36.6 \\
Average & Methanol & $664.8 \pm 0.99^{\mathrm{i}}$ & 36.7 \\
741 & & $993.5 \pm 0.68^{\mathrm{e}}$ & 54.9 \\
& Acetone & 773.5 & 42.7 \\
Average & Ethanol & $707.4 \pm 1.32^{\mathrm{h}}$ & 39.1 \\
CV (\%) & Methanol & $489.5 \pm 3.98^{j}$ & 27.0 \\
\hline
\end{tabular}

* Mean values followed by the same letter in the column are not significantly different at $p<0.05$

** Values calculated taking 1809.9 of Ababuna and methanol as a base to compare with others

a standard antioxidant. The interaction effect of solvents and coffee pulps showed highly significant $(p<0.001)$ effects on DPPH scavenging capacity. The percentage of $\mathrm{DPPH}$ free radical scavenging activity of different types of coffee pulps as affected by the type of extracting solvent is shown in Fig. 1. In the methanolic extract, the scavenging activity ranged from $17.3 \%$ (741) to $70.2 \%$ (Ababuna). In the acetone extract, the scavenging activity ranged from $9.8 \%$ (74110) to $50 \%$ (Dessu). In the ethanolic extract, the scavenging activity ranged from $7.5 \%$ (741) to 37.3 (Ababuna).

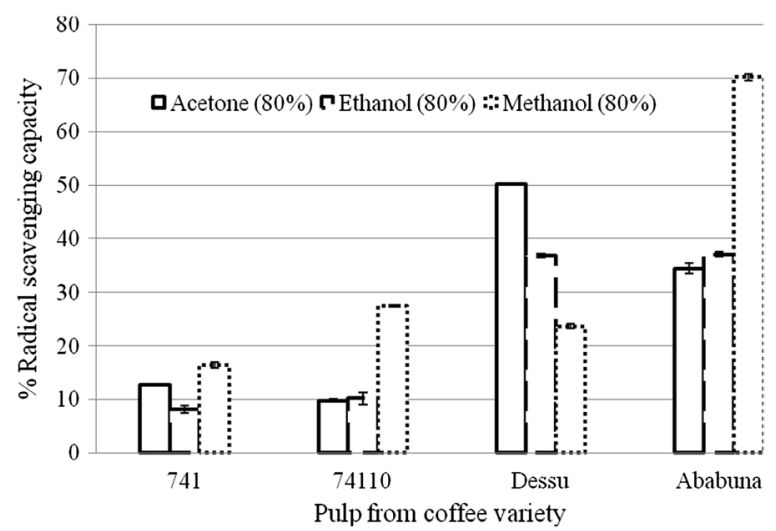

Fig. 1 DPPH radical scavenging activity of aqueous methanol, acetone and ethanol extracts from different varieties of coffee pulps
The methanol extract from the hybrid of Ababuna showed the highest antioxidant activity (70.2 \%), which is in line with its high polyphenol content. This shows the potency of the extract from the hybrid for use as a good source of antioxidants. The lowest scavenging activity (7.5 and $10 \%$ ) was measured from $80 \%$ ethanol extract of 741 and $80 \%$ acetone extract of 74110 varieties. However, the scavenging activity of the standard (ascorbic acid) (93\%) was higher as compared to the different coffee pulp extracts. The results of this study are also in line with the reports of Murthy and Naidu [4], who reported the percentage free radical scavenging activity of coffee pulp to be $65 \%$. The discrepancy might be due to the difference in the type of coffee pulp and extraction solvent used, since they used aqueous iso-propanol (60\%) as the extraction solvent.

The extracts that perform the highest antioxidant activity (Fig. 1) have the highest concentration of polyphenols (Table 1). Polyphenols are very important plant constituents, because of their scavenging ability on free radicals due to their hydroxyl groups. This is in good agreement with Sultana and Anwar [24] who reported that, with the increase in concentration of polyphenol compounds, DPPH free radical scavenging capacity increases and thus antioxidant activity increases. Therefore, the polyphenol content of plants may contribute directly to their antioxidant action [25]. Another case extract from the Dessu variety showed higher percentage of radical scavenging 
Table 2 Interaction effect of variety and solvents on the DPPH scavenging assay $\mathrm{IC}_{50}$ value $(\mathrm{mg} / \mathrm{ml})$

\begin{tabular}{lll}
\hline Variety & Solvents & $\begin{array}{l}\mathbf{I C}_{\mathbf{5 0}} \text { value } \\
(\mathbf{m g} / \mathbf{m l})^{*} \pm \mathbf{S E}\end{array}$ \\
\hline Ababuna & Acetone & $4.4 \pm 0.05^{\mathrm{c}}$ \\
& Ethanol & $2.4 \pm 0.05^{\mathrm{b}}$ \\
Dessu & Methanol & $0.4 \pm 0.01^{\mathrm{a}}$ \\
& Acetone & $1.1 \pm 0.03^{\mathrm{ab}}$ \\
74110 & Ethanol & $4.1 \pm 0.17^{\mathrm{c}}$ \\
& Methanol & $8.4 \pm 0.72^{\mathrm{e}}$ \\
741 & Acetone & $15.8 \pm 0.10^{\mathrm{h}}$ \\
& Ethanol & $15.4 \pm 0.16^{\mathrm{h}}$ \\
& Methanol & $6.2 \pm 0.39^{\mathrm{d}}$ \\
$\mathrm{CV}(\%)$ & Acetone & $13.6 \pm 0.11^{\mathrm{g}}$ \\
& Ethanol & $22.6 \pm 0.16^{\mathrm{i}}$ \\
& Methanol & $11.3 \pm 0.11^{\mathrm{f}}$ \\
\hline $\mathrm{M}$ & & 5 \\
\hline
\end{tabular}

* Mean values followed by the same letter in the column are not significantly different at $p<0.05$

activity in acetone. This is also in accordance with other studies $[26,27]$ that reported that $80 \%$ acetone was the most suitable solvent for the extraction of DPPH scavenging compounds from barley and legumes.

The inhibition concentration $\left(\mathrm{IC}_{50}\right)$ value for the DPPH scavenging assay was calculated for all the four solvent extracts of coffee pulps. $\mathrm{IC}_{50}$ value is defined as the concentration of antioxidant required for $50 \%$ scavenging of DPPH radicals. It is a parameter widely used to measure antioxidant activity of biological and nonbiological compounds. A smaller $\mathrm{IC}_{50}$ value corresponds to a higher antioxidant activity of the plant extract [28], since it requires less concentration to achieve the same value. In the present study, the lowest $\mathrm{IC}_{50}$ values of 0 . $4 \mathrm{mg} / \mathrm{ml}$ was obtained when a hybrid of Ababuna was extracted with methanol, which indicated its powerful free radical scavenging ability followed by the acetone extract of the Dessu pulp $(1.1 \mathrm{mg} / \mathrm{ml})$ (Table 2). According to this study, to achieve $50 \%$ equal inhibition of free radicals, the required concentration by 74110 and 741 is 15.5 and 28.3 times more as compared to the extract of Ababuna, respectively. The highest $\mathrm{IC}_{50}$ value $(22.6 \mathrm{mg} /$ $\mathrm{ml}$ ) was obtained when 741 was extracted with ethanol, which indicated its least potent antioxidant activity. Due to higher values of total polyphenols and antioxidant activity of methanolic extracts except acetone in the case of Dessu, the lowest $\mathrm{IC}_{50}$ value was also estimated when methanol was used as a solvent. Azlim Almey and others [29] showed that the difference in $\mathrm{IC}_{50}$ values between methanolic and ethanolic extracts might be due to the intrinsic properties of plant compounds and their interaction with the solvents used. Even though a methanolic extract of Ababuna showed higher antioxidant activity, however, statistically, it was not different $(p>0.05)$ from the acetone extract of Dessu. In this study, the $\mathrm{IC}_{50}$ values of cherry pulp from hybrid and other coffee varieties has been determined for the first time, and hence no literature data are available to compare our results with information from other literature.

\section{Conclusions}

Coffee is one of the hot beverages consumed copiously every day throughout the world by millions of people. Even though the quality coffee is determined by the type of coffee variety, premium quality coffee comes from washed coffee of wet processing units than unwashed coffee from dry processing methods. However, coffee cherry pulping, fermentation and washing of parchment in the wet processing method discharges million tons of fresh coffee cherry pulp to the environment. But as a waste utilization strategy and value addition process, pulps discarded into the environment can be used to extract valuable ingredients for use as an additive in the food and pharmaceutical industries. The current study showed that total polyphenols, antioxidant capacity and free radical inhibition concentration varied among coffee pulps from different varieties and the type of solvent used for extraction. Waste pulp from Ababuna exhibited better total polyphenol content, antioxidant capacity and $\mathrm{IC}_{50}$ value when $80 \%$ methanol was used as an extraction solvent. Among solvent types, the same solvent showed better extraction efficiency for all pulps except Dessu. Therefore, extraction of such type of valuable bioactive compounds from coffee pulp discarded as a waste could add value to improve the economic value of coffee pulp waste. Furthermore, coffee cherry pulp can be used as an alternative source to extract polyphenols and antioxidant compounds for the benefit of human health.

\section{Authors' contributions}

MG carried out most of the research works and wrote the paper, YBT was involved in developing the concept and part of the research activities as well as in editing the manuscript, AS was involved in facilitating research work and editing the manuscript. All authors read and approved the final manuscript.

\section{Author details}

1 Jimma University College of Agriculture and Veterinary Medicine, PO. BOX 307, Jimma, Ethiopia. ${ }^{2}$ Ethiopian Institute of Agricultural Research, Jimma Agricultural Research Center, POX 192, Jimma, Ethiopia.

\section{Acknowledgements}

The authors thank the Jimma Agricultural Research Center for supplying coffee pulps and the Jimma University College of Agriculture and Veterinary Medicine of Ethiopia and PHMIL project of Global Affairs of Canada for financial support to conduct this research.

\section{Competing interests}

The authors declare that they have no competing interests.

Received: 15 May 2016 Accepted: 7 July 2016

Published online: 26 September 2016 


\section{References}

1. Moure A, Cruz JM, Franco D, Dominguez JM, Siniero JMJ, Dominguez $\mathrm{H}$, et al. Natural antioxidants from residual sources. Food Chem. 2001;72:145-8.

2. Chen C, Pearson AM, Gray Jl. Effects of synthetic antioxidants (BHA, BHT and PG) on the mutagenicity of IQ-like compounds. Food Chem. 1992:43(3):177-83.

3. Kahl R, Kappus H. Toxicology of the synthetic antioxidants BHA and BHT in comparison with the natural antioxidant vitamin E. Zeitschrift fur Lebensmittel-untersuchung und-forschung. 1993;196(4):329-38.

4. Murthy PS, Naidu MM. Recovery of polyphenols antioxidants and functional compounds from coffee industry by-products. Food Bioprocess Technol. 2012;5(3):897-903.

5. Roussos S, Aquiáhuatl MA, Trejo-Hernández MR, Perraud IG, Favela E, Ramakrishma M, Raimbault M, Viniegragonzález G. Biotechnological management of coffee pulp-isolation, screening, characterization, selection of caffeine-degrading fungi and natural microflora present in coffee pulp and husk. Appl Microbiol Biotech. 1995:42:756-62.

6. Navia PDP, Velasco MRDJ, Hoyos CJL. Production and evaluation of ethanol from coffee processing by-products. Vitae. 2011;18(3):287-94.

7. Braham JF, Bressani S. Coffee pulp: composition, technology and utilization. International Development Research Center, Ottawa, Canada. 1979: IDRC-108e.

8. Oreopoulou V, Tzia C. Utilization of plant by-products for the recovery of proteins, dietary fibers, antioxidants, and colorants. In: Oreopoulou V, Russ W, editors. Utilization of by-products and treatment of waste in the food industry. New York: Springer; 2007. p. 209-32.

9. Arvanitoyannis IS, Tserkezou P. Wheat, barley and oat waste: a comparative and critical presentation of methods and potential uses of treated waste. Int J Food Sci Technol. 2008;43(4):694-725.

10. Torres-Mancera MT, Cordova-López J, Rodríguez-Serrano G, Roussos S, Ramírez-Coronel MA, Favela-Torres E, Saucedo-Castañeda G. Enzymatic extraction of hydroxycinnamic acids from coffee pulp. Food Techno Biotechnol. 2011;49:369-73.

11. Pushpa S, Murthy MR, Manjunatha G, Sulochannama M. Extraction, characterization and bioactivity of coffee anthocyanins. Eur J Biol Sci. 2012;4(1):13-9.

12. Saewan N, Atisakul K, Mana T, Jimtaisong A, Kittigowittana K. Antioxidant capacity of different levels of ripeness and parts of Coffea arabica extracts. Pure and applied chemistry international conference. 2012.

13. Jagtap UB, Bapat VA. Antioxidant activities of various solvent extracts of custard apple (Annona squamosa L.) fruit pulp. Nutrafoods. 2012;11(4):137-44.

14. Singleton VL, Orthofor R, Raventos RML. Analysis of total phenols and other oxidation substrates and antioxidants by means of Folin-Ciocaltau reagent. Methods Enzymol. 1999:299:152-78.

15. Conforti F, Statti G, Uzunov D, Menichini F. Comparative chemical composition and antioxidant activities of wild and cultivated Laurus nobilis L. leaves and Foeniculum vulgare subsp. piperitum (Ucria) coutinho seeds. Biol Pharm Bull. 2006;29(10):2056-64.
16. Hemalatha S, Lalitha P, Arulpriya P. Antioxidant activities of the extracts of the aerial roots of Pothos aurea (Linden ex Andre). Der Pharma Chemica. 2010:2(6):84-9.

17. Vladimir-Knežević S, Blažeković B, Bival Štefan M, Babac M. Plant polyphenols as antioxidants influencing the human health. Phytochemicals as nutraceuticals-global approaches to their role in nutrition and health; 2012. p. 155-80.

18. Gorinstein S, Zachwieja Z, Katrich E, Pawelzik E, Haruenkit R, Trakhtenberg S. Martin-Belloso O. Comparison of the contents of the main antioxidant compounds and the antioxidant activity of white grapefruit and his new hybrid. LWT-Food Sci Technol. 2004:37(3):337-43.

19. Lattanzio V, Lattanzio VM, Cardinali A. Role of phenolics in the resistance mechanisms of plants against fungal pathogens and insects. Phytochem Adv Res. 2006:661:23-67.

20. Siddiq A, Anwar F, Manzoor M, Fatima A. Antioxidant activity of different solvent extracts of Moringa oleifera leaves under accelerated storage of sunflower oil. Asian J Plant Sci. 2005;4(6):630-5.

21. Yao LH, Jiang YM, Datta N, Singanusong R, Liu X, Duan J, Raymont K, Lisle A, Xu Y. HPLC analyses of flavanols and polyphenols acids in the fresh young shoots of tea (Camellia sinensis) grown in Australia. Food Chem. 2004;84(2):253-63.

22. Turkmen N, Sari F, Velioglu YS. Effects of extraction solvents on concentration and antioxidant activity of black and black mate tea polyphenols determined by ferrous tartrate and Folin-Ciocalteu methods. Food Chem. 2006:99(4):835-41.

23. Halliwell B, Murcia MA, Chirico S, Aruoma Ol. Free radicals and antioxidants in food and in vivo: what they do and how they work. Crit Rev Food Sci Nutr. 1995;35(1-2):7-20.

24. Sultana B, Anwar F. Flavonols (kaempferol, quercetin, myricetin) contents of selected fruits, vegetables and medicinal plants. Food Chem. 2008;108(3):879-84.

25. Tosun M, Ercisli S, Sengul M, Ozer H, Polat T, Ozturk E. Antioxidant properties and total phenolic content of eight Salvia species from Turkey. Biol Res. 2009:42(2):175-81.

26. Zhao H, Dong J, Lu J, Chen J, Li Y, Shan L, Gu G. Effects of extraction solvent mixtures on antioxidant activity evaluation and their extraction capacity and selectivity for free phenolic compounds in barley (Hordeum vulgare L.). J Agric Food Chem. 2006;54(19):7277-86.

27. Xu BJ, Chang SKC. A comparative study on phenolic profiles and antioxidant activities of legumes as affected by extraction solvents. J Food Sci. 2007;72(2):S159-66

28. Maisuthisakul $P$, Suttajit M, Pongsawatmanit R. Assessment of polyphenols content and free radical scavenging capacity of some Thai indigenous plants. Food Chem. 2007;100(4):1409-18.

29. Azlimalmey AA, Ahmedjalalkhan C, Syedzahir I, Mustaphasuleiman K, Aisyah MR, Kamarulrahim K. Total polyphenols content and primary antioxidant activity of methanolic and ethanolic extracts of aromatic plants' leaves. Int Food Res J. 2010;17(4):1077-83.

\section{Submit your manuscript to a SpringerOpen ${ }^{\circ}$ journal and benefit from:}

- Convenient online submission

- Rigorous peer review

- Immediate publication on acceptance

- Open access: articles freely available online

High visibility within the field

- Retaining the copyright to your article

Submit your next manuscript at springeropen.com 